\title{
DO PRAZER AO SOFRIMENTO NO TRABALHO DA ENFERMAGEM: o discurso dos trabalhadores ${ }^{a}$
}

\author{
A driane I nês KE SSL E R ${ }^{b}$, Suzane Beatriz Frantz KRU G ${ }^{c}$
}

\section{RESUM 0}

0 estudo teve como objetivo identificar situações causador as de prazer e de sofrimento no trabal ho da enfer magem de duas instituições de saúde, local izadas em área rural. T rata-se de uma pesquisa realizada na U niversidade de Santa Cruz do Sul (U NISC), teve abordagem qualitativa e os dados das entrevistas com 16 trabal hadores foram anal isados utilizando a $A$ nál ise de Conteúdo. 0 s resultados apontaram sofrimento no trabal ho rel acionado à assistência ao paciente, às precárias condições de trabal ho e à dificuldade de convívio da equipe; prazer no trabal ho relacionado ao reconhecimento pelos pacientes, à possibilidade de amenizar o sofrimento do mesmo, ao bom relacionamento da equipe de trabalho, ao acompanhamento da família nas necessidades de saúde eà resolutividade de demandas da comunidade. 0 enfrentamento do sofrimento está voltado a medidas individuais e institucionais. Consider a-se rel evante um ol har humanizado para a saúde do trabal hador da saúde com modificações na organização do trabalho.

D escritores: Enfermagem do trabalho. Satisfação no emprego. Condições de trabal ho.

\section{RESUMEN}

E I estudio busca identificar las situaciones que causan placer y sufrimiento en el trabajo de enfermería en dos instituciones de salud ubicadas el área rural. Se trata de una encuesta realizada en la U niversidad deSanta Cruz do Sul (U N ISC), tuvo un enfoque cual itati vo y datos de entrevistas con diecisés trabajador es fuer on analizados utilizando el análisis de contenido. L os resultados mostraron la angustia en los trabajos relacionados con el cuidado del paciente, las malas condiciones de trabajo y la dificultad de reunir el equipo; placer en el trabajo relacionado con el reconocimiento por parte de los pacientes, la posibilidad dealiviar el sufrimi ento de mismo, la buena relación entreel equipo detrabajo, el seguimiento de la familia sobrelas necesidades y demandas de sal ud resueltos de la comunidad. $L$ a cara de sufrimiento se refiere a medidas individuales einstitucional es. E $S$ pertinente una mirada humanizada de la salud del trabajador de la salud con los cambios en la organización del trabajo.

D escriptores: E nfer mería del trabajo. Satisfacción en el trabajo. Condiciones de trabajo.

Título: D el placer al sufrimiento en el trabajo de enfermería: el discurso de los trabajadores.

\section{ABST RACT}

This study aimed to identify situations that cause pleasure and pain in the nursing work in two health institutions located in rural areas. T his is a survey conducted at the U niversity of Santa Cruz do Sul (U N ISC). T he research had a qualitative approach and the data was collected through interviews with sixteen workers, later analyz ed through content analysis. The results show ed distress in work related to patient care, to poor w orking conditions and to difficulties in the relationship with the rest of the staff. P leasure in work was related to recognition by patients, to the possibility of alleviating the suffering of patients, to a good relationship with the rest of the staff, to the monitoring of the family on health needs and to theansw ering of demands by the community. Facing suffering is possi blethrough individual and institutional measures. A humanized look to the health of the health worker is relevant, with changes in work organization.

D escriptors: 0 ccupational health nursing. J ob satisfaction. W orking conditions.

Title: F rom pleasure to suffering in the nursing work: the speech of the workers.

\footnotetext{
a Artigo originado do trabalho de conclusão do Curso de Graduação em Enfermagem da Universidade de Santa Cruz do Sul (U NISC), apresentado em 2010

b Enfermeira na Sociedade Beneficente H ospital Candelária, Candelária, Rio Grande do Sul, Brasil.

' $D$ outora em Serviço Social, D ocente A djunta do D epartamento de Enfermagem e Odontologia da U NISC, Santa Cruz do Sul, Rio G rande do Sul, Brasil.
} 


\section{INT RODUÇÃO}

0 trabalho é uma atividade antiga e inerente ao ser humano, ocupa parte considerável da vida e compreende a subjetividade do sujeito, podendo ser fonte de sofrimento e de fadiga para uns e de prazer para outros. No cotidiano do trabal ho de enfermagem, observam-se jornadas exaustivas e ininter ruptas de plantões, sobrecarga de tar efas e condições precárias, seja de recursos humanos ou materiais, além da convivência com a dor e com 0 sofrimento alheio ${ }^{(1)}$. No entanto, estudos apontam que a val orização e o reconhecimento obtidos através de ações realizadas junto à comunidade e ao paciente, a fim de melhorar as condições de saúde, surgem como fontes de prazer e de satisfação pessoal na profissão(2). N esse sentido, o trabalho em ambiente hospitalar e na saúde pública é rico, estimulante e heterogêneo, mas engloba simultaneamente atividades insalubres, penosas e difíceis para todos os trabalhadores inseridos nesse meio(2).

Assim, pretendeu-se desvelar, que o processo de trabal ho da enfer magem não é somente sinônimo de sofrimento, existindo situações de prazer e satisfação para o profissional, tornando o trabal ho uma atividade prazerosa e lúdica. Por outro lado, a identificação das situações de sofrimento pode desencadear soluções e estratégias para modificar essa realidade, tornando o cotidiano satisfatório para os profissionais. A credita-se, que conhecer as situações de satisfação e insatisfação no trabal ho dessa categoria profissional, pode contribuir, em parte, para a luta por melhorias na qualidade de vida e de trabal ho desses trabal hadores.

A partir dessas percepções, pretendeu-se compreender de forma mais aprofundada essa questão. Sendo assim, os objetivos do estudo centraramse em identificar situações causadoras de prazer e de sofrimento no cotidiano de trabal ho da equipe de enfermagem; verificar o entendimento dos trabal hadores quanto a ações para minimizar condições de sofrimento e quanto a estratégias para a valorização de situações de satisfação no trabalho; conhecer as formas de enfrentamento do desgaste elaboradas pelos mesmos; identificar na visão da equipe, ações da instituição na prevenção de situações de sofrimento e ações disponibilizadas para a valorização do trabal ho da enfer magem.

U m fator determinante para a escolha dos locais de estudo foi a opção por investigar trabalha- dores de instituições de saúde que estivessem localizadas em área rural e que atendessem essa população ${ }^{\text {. A }}$ A intenção foi enfocar essa realidade por suas características e especificidades próprias, como fatores sociais, econômicos, políticos e culturais, que podem ser determinantes para a organização do trabal ho em saúde, e consequentemente, para o prazer e/ ou sofrimento no trabal ho.

A organização do trabalho na área rural é marcada, muitas vezes, pela produção agrícola ou pecuária em pequena extensão de terra, com mãode-obra da própria família. Assim a agricultura familiar tornou-se parte do chamado desenvolvimento sustentável, que além do plantio envolve a comercial ização de diversos produtos. Considerase 0 trabalho na agricultura como responsável, muitas vezes, pelo desenvolvimento econômico da região(3). Esse é o panorama do presente estudo, onde os produtores são dedicados à criação de suínos, aves ou gado leiteiro, voltados para o cultivo de milho, fumo, eucalipto ou frutas, ou, ainda, direcionados para a associação de diversas culturas.

\section{MET ODOLOGIA}

Consistiu em um estudo comparativo, de caráter exploratório-descritivo, com abordagem qualitativa que se originou de um estudo monográfico de conclusão de curso(4). Foi realizado em uma instituição hospitalar e uma unidade de saúde da família (U SF) de um município de 10.000 habitantes da zona rural do Vale do Rio Pardo, Rio G rande do Sul. A instituição hospitalar é de caráter geral e filantrópico, de pequeno porte, com atendimentos de média complexidade, possui 35 leitos e realiza em média 146,25 atendimentos/ mês. Já a U SF é dividida em seis micro-áreas, abrange 879 famílias, totalizando uma cobertura de 2.741 habitantes em sua região de abrangência.

Compuseram o estudo, três trabal hadores de enfermagem da USF e treze profissionais da instituição hospitalar, total izando dezesseis sujeitos. 0 instrumento de col eta de dados foi uma entrevista que abordou as seguintes questões norteadoras: se o trabal ho em enfermagem gera situações de sofrimento e prazer? E $m$ quais situações de trabal ho?

\footnotetext{
d Área rural: região com predominância da fonte de subsistência proveniente da agricultura familiar, (produção de tabaco, comercialização e produção de alimentos, etc).
} 
Quais ações podem minimizar as condições de sofrimento no trabalho? Quais estratégias podem val orizar a satisfação no trabal ho? Q uais mecanismos para enfrentar situações que tornam o trabaIho desgastante? Quais ações da instituição para prevenir o sofrimento no trabal ho evalorizar o trabalho de enfermagem?

Para o registro das informações foi utilizado equipamento digital de gravação, com base na assinatura do T ermo de Consentimento Livre e E sclarecido pelo sujeito. 0 desenvolvimento da pesquisa foi orientado pela Resolução 196/ 96 do Conselho $N$ acional de Saúde ${ }^{(5)}$, que regulamenta a pesquisa com seres humanos, com aprovação pelo Comitê de É tica da U niversidade de Santa Cruz do Sul (UNISC), sob protocolo n-2577/ 10, e pelos serviços de saúde em questão.

0 método de análise dos dados utilizado foi a A nálise de Conteúdo. T rata-se de um conjunto de técnicas de análise das comunicações que visam obter indicadores que permitam a inferência de conhecimentos relativos às condições de produção dessas mensagens ${ }^{(3)}$. A pós o levantamento de dados, o material foi organizado, sendo os dados transcritos em forma de texto, analisados e comparados entre eles, com base em referencial bibliográfico. A pós, foram definidas as categorias de análise: situações geradoras de prazer e de sofrimento no trabalho da enfermagem; práticas de enfrentamento do trabal hador às situações de sofrimento no trabalho; ações da instituição de saúde na prevenção do sofrimento e na valorização do trabalho.

\section{APRE SE NTAÇÃO E DISCUSSÃO DOS RE SULT ADOS}

Constatou-se que os sujeitos da pesquisa, em ambos os serviços de saúde, situaram-se na faixa etária entre 20 a 48 anos de idade e foram em sua maioria, do sexo feminino, reafirmando o fato de que a profissão é formada predominantemente por mulheres. 0 tempo de trabal ho dos sujeitos na instituição hospitalar concentrou-se na média de dez anos. N a U SF deve-se considerar que o serviço funciona apenas há dois anos e somente um profissional atua no serviço desde a sua implantação.

E $m$ ambos os serviços, os trabal hadores possuem um único vínculo empregatício. Percebeu-se esse dado como diferencial no estudo, pois na enfermagem, os profissionais, em sua grande maioria, apresentam mais de um vínculo de trabalho(6), muitas vezes, devido aos baixos salários da categoria que não suprem as necessidades dos trabal hadores, resultando em desgaste físico e mental dos mesmos.

Quanto à jornada e turnos de trabalho, no hospital, a grande maioria dos sujeitos perfaz 36 horas semanais e trabalha em turnos alternados, enquanto que na USF a equipe realiza 40 horas semanais e atua no turno diurno.

\section{Situações geradoras de prazer e de sofrimento no trabalho da enfermagem}

As situações que ocasionam sofrimento aos trabal hadores dos dois serviços de saúde foram distintas entre si. No hospital, dentre os aspectos causadores de desgaste aos profissionais de enfermagem, destacaram-se a falta de equipamentos e de recursos humanos e o sofrimento e a morte do paciente. As dificuldades sentidas em relação à falta de equipamentos e recursos humanos são características peculiares da área da saúde, em que os trabal hadores, muitas vezes, necessitam ajustar recursos finitos a necessidades de cuidado de saúde da populaçãa ${ }^{(1-7)}$. Esta questão acaba refletindo negativamente na qualidade da assistência à saúde, fato este evidenciado no depoimento a seguir:

[ ...] eu já falei até já várias vezes que isso de noite a gente é sozinho até certa hora, dependendo do que acontecer, se tiver uma emergência ou coisa assim uma pessoa não resolvea emergência né. A pessoa não morre porque não era pra morrer, porque tu não consegue resolver uma parada cardíaca sozinho [ ...] eles [ os gestores] lutam pela parte financeira, mas a gente trabalha com vidas [ ...] se tu ta sozinho eta atendendo um, o outro ta chamando, tu tenque deixar deatender, tu tem que avaliar quem precisa primeiro (T rab. Enferm. 9 H ospital).

Os trabalhadores do hospital também referiram o sofrimento e morte do paciente como fatores de difícil convivência a serem enfrentados na atividade laboral. Cabe sal ientar que é neste cenário que os profissionais de enfermagem convivem diariamente, ou seja, lutam pela vida e contra a morte, tomam para si a responsabilidade de salvar, curar ou mesmo aliviar a dor, já que a morte, na maioria das vezes, é vista como um fracasso, sendo, portanto, de difícil aceitação ${ }^{(8,9)}$.

Já na U nidade de Saúde da Família (USF), destacou-se como fator de desgaste no trabalho, 
a lentidão no fluxo do serviço, muitas vezes, ocasionada pelo excesso de exigências burocráticas nas solicitações e encaminhamentos de exames e consultas especializadas. As desigualdades no acesso e na utilização dos serviços de saúde pelos usuários são conseqüências de barreiras organizacionais que apontam a necessidade de repensar a estrutura dos atendimentos, principalmente o fluxo do usuário na rede de serviço. 0 relato a seguir descreve esse cenário:

[ ...] tu sabe pra quem tu vai manda, só que esse tempo deveria ser mais rápido, deveria sair daqui o paciente do ESF encaminhado pra tal lugar pra tal hora e pra tal dia, mas isso às vezes a gente não pode fazer, se perde muito tempo enrolando o paciente, mandando de um lugar pro outro, poderia já ta mantendo o tratamento (T rab. Enferm. 2 U SF).

O utra concepção referida pela equipe de enfermagem da USF foi a não resolutividade das situações ditas "sociais", como as condições precárias de moradia, saneamento e baixa renda, pois estas, segundo os trabalhadores, não são suas atribuições, entretanto, repercutem na qualidade da assistência ao usuário. E specificamente na área rural estudada, a precária realidade econômica e social dos usuários da USF, constitui-se como agravante do sofrimento dos trabal hadores da saúde. Os profissionais de saúde, sozinhos, não conseguem dar conta dessa demanda de solicitações, necessitando de diretrizes e políticas de saúde que possam traduzir-se em ações que não originem tamanha quantidade de casos a serem atendidos ${ }^{(10)}$.

U m fator contributivo para insatisfação no trabal ho citado pelos trabalhadores dos dois serviços de saúde é a falta de reconhecimento e valorização das atividades desempenhadas, tanto por colegas da equipe de trabalho, quanto por gestores das instituições. A presentam-se como prioridades a produtividade eresolutividade no trabal ho, 0 que acaba, muitas vezes, gerando sobrecarga aos trabalhadores.

A pesar das dificuldades apresentadas, várias fontes de prazer no trabalho também foram referidas destacando-se, em ambos os serviços, o reconhecimento profissional proveniente dos pacientes, exposto em manifestações verbais e de gratidão pelo serviço prestado. Esse sentimento de gratidão, comum aos habitantes de áreas rurais, em que as dificul dades vividas no cultivo da ag ricultura acabam aproximando o convívio entre os mo- radores, é acentuado pelas características culturais de solidariedade e reconhecimento pelo auxílio prestado.

$\mathrm{N} \mathrm{a}$ instituição hospitalar, a satisfação no trabalho referiu-se também a possibilidade de amenizar o sofrimento do paciente e da melhoria do seu quadro de saúde. I sso significa que, apesar de conviver com situações de sofrimento e morte, a equipe tem momentos de sucesso, que se tornam gratificantes e trazem satisfação. 0 bom relacionamento da equipe de trabal ho também foi destacado como gerador de prazer na atividade laboral, fato este diverso de outras realidades de equipes de enfermagem em que as relações interpessoais surgem como gerador de insatisfação. Entendese que a complexidade do relacionamento no trabal ho envolve diversos fatores que possibilitam ao trabalhador, conviver com maior ou menor habilidade com seus pares nos locais de trabalho(6-11). Essa característica positiva do ambiente de trabal ho em realidades rurais acentua a parceria e 0 companheirismo entre colegas.

$\mathrm{Na}$ U SF, o fator de prazer no trabal ho consiste, segundo os trabal hadores, no acompanhamento da família em suas necessidades de saúde e na resolutividade de demandas sociais da comunidade. Esses fatos foram evidenciados nos depoimentos a seguir:

[ ...] a questão da saúde da família, do acompanhamento da família, tu acompanhar uma gestante, depois tu acompanhar aquele bebe, tu ter o vinculo com aquela família, isso pra mim gera bastante prazer saber onde aquela família mora, como mora, como serelaciona entre eles, então ter assim, esse envolvimento com a família ( $T$ rab. Enferm. 1 USF).

[ ...] uma situação com um paciente idoso, que vivia em uma situação social inaceitável, não tinha familiares, ninguém pra cuidar dele, vivia numa situação desumana, então tu conseguir que o paciente fosse para um lar de idosos pra ser bem cuidado, saber que ele tá bem agora, que ele tá feliz, tá gostando de ficar lá, isso megerou um prazer enorme (T rab. Enferm. 1 U SF).

A precária situação social, econômica, e cultural dos usuários dos serviços precisam ser entendidas pelos trabalhadores, como demandas de cunho social indispensáveis, que necessitam ser priorizadas para resolução das reais necessidades de saúde da população(10). Ressalta-se que a resolutividade das demandas sociais na USF foi consi- 
derado, ao mesmo tempo, por seus trabalhadores, como fator de sofrimento e de prazer no trabal ho. Esse aspecto atribui-se ao reconhecimento da comunidade rural pelo trabal ho da equipe de saúde, mas também dificultado, muitas vezes, por questões burocráticas que limitam a ação dos profissionais de saúde na resolutividade dos problemas.

\section{Práticas de enfrentamento do trabalhador às situações de sofrimento no trabalho}

E $m$ situações de sofrimento provocadas pelo trabal ho é comum que o trabal hador adote estratégias defensivas com a finalidade de se proteger $e$ prevenir o mesmo. Quando o rearranjo da organização do trabal ho não é mais possível e é bloqueado, o sofrimento inicia, a energia pulsional que não acha descarga no exercício do trabal ho se acumula no aparel ho psíquico, ocasionando um sentimento de desprazer e tensão(12).

E $m$ ambos os serviços de saúde, o lazer traduzido por atividades físicas, viagens e festividades, foi apontado pelos sujeitos como medidas para diminuir o estresse e a ansiedade ocasionados pela atividade laboral ${ }^{(10)}$.

No hospital, além desse fator, o diálogo entre a equipe foi referido como prática de enfrentamento e minimização do sofrimento. Pode-se perceber também a cautela dos profissionais de enfermagem do hospital ao referirem não compartilhar as vivências desgastantes do ambiente de trabal ho com seus familiares, o que retrata, de certa forma, uma tentativa de "poupá-los" e também de esquecer 0 que é vivenciado no trabal ho.

E m contrapartida, na USF, os trabalhadores acreditam que a escuta e 0 amparo familiar é fundamental para enfrentar as situações desgastantes no trabalho. Pressupõe-se que é considerado saudável desconectar-se da atividade profissional no ambiente familiar, a fim de, possibilitar a reflexão sobre o vivido em busca de estratégias saudáveis de enfrentamento ${ }^{(11,13)}$. E stas estratégias, assim como o amparo espiritual e religioso evidenciado pelos trabalhadores da U SF indicam a busca pelo bem-estar emocional.

\section{Ações da instituição de saúde na prevenção do sofrimento e na valorização do trabalho}

No intuito de proporcionar melhores condições de trabal ho, as instituições estudadas adotam, conforme referência dos trabalhadores, medidas de prevenção do sofrimento e valorização do trabalho.

$\mathrm{Na}$ instituição hospitalar, os sujeitos apontaram ações de educação continuada como palestras, treinamento em serviço e participação em eventos científicos que resultam na melhoria da qualificação profissional, entretanto, conforme relatado, ainda oferecidas com pouca frequência aos trabal hadores. A lém das estratégias individuais, os profissionais utilizam também, estratégias coletivas, como reuniões de equipe e encontros de confrater nização, para aliviar as tensões do ambiente de trabalho ${ }^{(14,15)}$. Para transformar um trabalho fatigante em prazeroso, precisa-se flexibilizar a organização do trabalho, de modo a deixar maior liberdade ao trabal hador para organizar seu serviço e encontrar gestos capazes de for necer prazer no ambiente de trabalho, diminuindo sua carga psíquica ${ }^{(12)}$.

Além disso, a pesquisa de satisfação realizada junto aos pacientes no hospital foi citada como forma de valorizar o trabal ho da equipe de enfermagem e também, uma alternativa para amenizar o sofrimento. Segundo os trabalhadores, em diversas situações, os pacientes elogiam o trabal ho da enfermagem, no entanto, os resultados sobre 0 desempenho da equipe e do serviço são pouco divulgados pela instituição. Estas pesquisas constituem-se em uma forma de avaliar e reconhecer a qual idade técnica dos profissionais de saúde ${ }^{(16)}$.

$\mathrm{Na}$ USF, os trabal hadores entendem que ações de educação continuada são determinantes para a qualificação profissional e, consequentemente, para a qualidade da assistência prestada ao paciente, constituindo-se como uma estratégia institucional para a val orização do trabal hador ${ }^{(17)}$, porém, essa prática, conforme evidenciado nas entrevistas, não se estende a todos os integrantes da equipe. Referem que o reconhecimento do trabalho ocorre somente através de manifestações verbais, não formais, por parte da coordenação do serviço, relacionado à produtividade e cumprimento das metas previstas. Esse aspecto configura exigências capitalistas quanto ao rendimento no trabaIho, em que os trabalhadores apontam exigências incessantes por produtividade e resolutividade no trabalho em saúde, denotando uma relação mercantilista, que reflete na qualidade de vida dos profissionais submetidos a pressões físicas e psíquicas ${ }^{(8)}$. 


\section{Ações a serem disponibilizadas pela instituição: concepções dos trabalhadores}

Os sujeitos do estudo dos dois ser viços de saúde apontaram o acompanhamento psicológico e grupos de auto-ajuda, como ações primordiais a serem ainda disponibilizadas pelas instituições de trabal ho, para auxiliar no reconhecimento de limites e compartilhar situações desgastantes vivenciadas com o usuário do serviço e equipe de trabaIho ${ }^{(14)}$. Foram também citadas questões referentes à diminuição da carga de trabal ho e estabel ecimento do piso salarial da categoria, ações estas que devem ser reivindicadas e discutidas pela categoria, a fim de minimizar os fatores condicionantes das doenças relacionadas ao trabalho.

No hospital destacou-se, ainda, uma maior disponibilidade de recursos financeiros e investimentos em recursos humanos para suprir a demanda do serviço e aprimorar a qualidade da assistência, assim como, o investimento em educação continuada. T ambém foi evidenciada maior valorização profissional da equipe de trabalho pela instituição, ação esta, que poderia ser desencadeada com o retorno dos resultados da pesquisa de satisfação realizada junto aos pacientes.

$\mathrm{N}$ a USF, percebeu-se que a falta de diálogo e de decisões conjuntas e compartilhadas, aparecem como fragilidades que necessitam ser aprimoradas para a melhoria do relacionamento interpessoal e da organização do trabalho na unidade. Além disso, os trabalhadores anseiam por políticas públicas de saúde que agilizem e promovam resolutividade de situações sociais e demandas da comunidade e pelo reconhecimento profissional por parte dos integrantes da equipe de trabal ho.

\section{CONSIDERAÇÕES FINAIS}

As realidades dos serviços de saúde estudados podem gerar situações de prazer e de sofrimento aos trabal hadores e, especificamente, no presente estudo, podem somar-se às influências da realidade social e cultural da área rural. 0 estudo em distintos serviços de saúde, cada qual com sua realidade de trabal ho e localizados em zona rural foi um diferencial da pesquisa, pois, apesar da mesma localização geográfica, foi possível identificar situações de prazer e sofrimento distintas, mas também comuns entre os mesmos. Percebeu-se que muitas dessas situações não são distintas de servi- ços de saúde localizados em áreas não rurais, demonstrando que, as características de uma região parecem não influenciar no prazer e/ ou sofrimento no trabal ho da enfermagem.

A partir da análise percebeu-se que os trabaIhadores de enfermagem, ora vivenciam situações de satisfação, or a de sofrimento. N o entanto, podese considerar que o prazer ocasionado pelo trabaIho pode, em muitas situações, tor nar-se um mecanismo de defesa para minimizar o sofrimento.

E mergiram sentimentos comuns de insatisfação no trabalho entre os profissionais dos dois serviços, relacionados ao não reconhecimento profissional das atividades desempenhadas. Além disso, a prioridade por produtividade no trabal ho apresentou-se como gerador de sobrecarga na jornada diária, oriundo da intensa demanda por atendimentos e número insuficiente de profissionais, resultando em insatisfação profissional e em desgaste físico e psicológico. E m contrapartida, o reconhecimento do trabalho pelos usuários do serviço é gerador de prazer na atividade laboral e estímulo necessário para enfrentar as situações desgastantes do ambiente de trabal ho.

I mportante destacar os fatores de prazer no trabal ho distintos entre os serviços estudados, sendo que a equipe da instituição hospitalar destacou como ponto de satisfação, o bom relacionamento entre a equipe de enfermagem. $\mathrm{Na} U \mathrm{SF}, 0$ prazer no trabal ho consiste em acompanhar as famílias em suas necessidades de saúde e solucionar demandas sociais da comunidade.

Quanto às práticas de enfrentamento do sofrimento adotadas no trabalho pelos trabal hadores dos serviços, o lazer foi apontado como uma alternativa para vencer o estresse. 0 compartilhamento das vivências desgastantes do ambiente de trabalho com os familiares é uma medida compreendida distintamente entre os profissionais dos dois serviços; na instituição hospitalar os trabaIhadores têm por hábito evitar essa prática; já na USF, a equipe vê isso como uma estratégia defensiva para enfrentar o que vivenciam diariamente.

Com relação às ações disponibilizadas pela instituição para prevenir o sofrimento e valorizar o trabalho, os profissionais do hospital evidenciaram que existem ações de educação continuada oferecidas com pouca frequência à equipe. $\mathrm{Na} U \mathrm{SF}$, essas ações também são oferecidas, mas, não se estendem a todos os integrantes da equipe. 
Foi constatada unanimidade entre os trabaIhadores dos dois serviços quanto à necessidade de acompanhamento psicológico e grupos de auto-ajuda para valorizar e enfrentar o desgaste no trabaIho. D estacou-se também o investimento em educação continuada e recursos humanos para suprir a demanda na instituição hospitalar. N a U SF existe a necessidade por melhoria no relacionamento interpessoal da equipe e da organização do trabaIho na unidade.

0 estudo pode contribuir para estímulo à discussão das questões de saúde no trabalho da enfermagem, pois a identificação de situações geradoras de sofrimento propicia o desencadeamento de reflexões sobre a forma como o trabalho vem sendo organizado. Ressalta-se, portanto, a importância de um ol har humanizado e atencioso para a saúde do trabalhador da saúde por parte das instituições de trabalho, assim como, medidas centradas em mudanças na organização do trabalho, com 0 objetivo de promover o bem-estar e evitar 0 adoecimento desse trabalhador.

\section{REFERÊNCIAS}

1 Caregnato RCA, M utti R. Pesquisa qualitativa: análise de discurso ver sus análise de conteúdo. T exto Contexto Enferm. 2006;15(4):679-84.

2 Vieira ABD, Kamada I, Alves ED. Cuidando do cuidador: percepções e concepções de auxiliares de enfermagem acerca do cuidado de si. Texto Contexto Enferm. 2007;16(1):15-20.

3 Almeida PJ S, Pires DE P. 0 trabalho em emergência: entre o prazer e o sofrimento. Rev Eletrônica Enferm [ Internet] . 2007 [ citado 2010 abr 03];9(3):617-29. D isponível em: http:/ / www.fen.ufg.br/ revista/ v9/ n3/ v9n3a05.htm.

4 Kessler AI, Krug SBF. Do prazer ao sofrimento no trabalho da enfermagem: o discurso dos trabalhadores [ monografia]. Santa Cruz do Sul: Univer sidade de Santa Cruz do Sul; 2010.

5 M inistério da Saúde (BR ), Conselho N acional de Saúde. Resolução 196, de 10 de outubro de 1996: diretrizes e normas regulamentadoras de pesquisa envolvendo seres humanos. Brasília (DF ); 1996.

\section{Endereço da autora / Dirección del autor / Author's address:}

Adriane Inês Kessler

L inha G eneral Osório, Interior

96859-000, Santa Cruz do Sul, RS

E -mail: adrianeineskessler@yahoo.com.br
6 Barbosa R. A economia solidária como política pública: uma tendência de geração derenda eressignificação do trabalho no Brasil. São Paulo: Cortez; 2006.

7 M edeiros SM, Ribeiro L M , Fernandes SM BA, Veras VSD. Condições de trabalho e enfermagem: a transver sal idade do sofrimento no cotidiano. Rev E letrônica E nferm [ I nternet] . 2006 [ citado 2010 out 26];8(2): 233-40. D isponível em: http:/ / www.fen.ufg.br/ revista/ revista8_2/ v8n2a08.htm.

8 A mestoy SC, Cestari M E, T hofehrn M B, M ilbrath VM . Características institucionais que interferem na lider ança do enfermeiro. Rev Gaúcha Enferm. 2009; 30(2):214-20.

9 Stumm E M F, M açalai RT, Kirchner RM . Dificuldades enfrentadas por enfermeiros em um centro cirúrgico. T exto Contexto Enferm. 2006;15(3):464-71.

10 Sousa DM , Soares E O, Costa KM S, Pacífico ALC, Parente ACM . A vivência da enfer meira no processo de morte e morrer dos pacientes oncológicos. T exto Contexto Enferm. 2009;18(1):41-7.

11 Krug SBF. Sofrimento no trabalho: a construção social do adoecimento de trabal hadoras da saúde [ tese] . Porto Alegre: Pontifícia U niversidade Católica do R io Grande do Sul; 2006

12 Camelo SH H. Riscos psicossociais relacionados ao stress no trabal ho das equipes de saúde da família e estratégias de ger enciamento [ tese] . São Paulo: U niversidade de São Paulo; 2006.

13 Dejours C. A loucura do trabalho: estudo de psicopatologia do trabalho. São Paulo: Cortez; 1992.

14 Corradi E M , Zgoda LT RW, Paul M F B. O gerenciamento de conflitos entre a equipe de enfermagem. Cogitare E nferm. 2008;13(2):184-93.

$15 \mathrm{M}$ artins JT, Robazzi M LCC. 0 trabal ho do enfermeiro em unidade de terapia intensiva: sentimentos de sofrimento. Revista L atino-A m E nfer magem. 2009;17(1):52-8.

16 Pacheco APF, Fernandes EOM , M oretto IG, Souza AIJ, Wayhs RI, Coelho IG, et al. 0 trabalhador de enfermagem em oncologia pediátrica: repercussões na vida profissional efamiliar [ monografia] . Florianópolis: U niversidade Federal de Santa Catarina; 2008.

17 Vaitsman J, Andrade G RB. Satisfação e responsividade: formas de medir a qualidade e a humanização da assistência à saúde. Ciênc Saúde Colet. 2005;10(3):599-613.

Recebido em: 20/ 05/2011

A provado em: 01/ 03/ 2012 